\title{
Merchandising na visão do consumidor: uma análise da prática do cross merchandising
}

\section{Merchandising in the consumer vision: an analysis of cross merchandising practice}

Taís Pasquotto Andreoli Doutora em Administração. Professora Adjunta Unifesp - Brasil. Tais.andreoli@unifesp.br Taís Irani Oliveira Graduanda em Administração. Faculdade Anhanguera - Brasil.

Tais.irani@anhanguera.br

\section{RESUMO}

O trabalho teve como objetivo analisar a avaliação da prática de cross merchandising na opinião dos consumidores. Procedeu-se, inicialmente, a uma revisão da literatura, focando na discussão acerca do merchandising, sua origem e evolução, seu conceito e sua importância, adentrando à prática de cross merchandising. Tendo a literatura como suporte, adotou-se metodologicamente, uma abordagem quantitativa, de cunho exploratório, realizada por meio de dois levantamentos quantitativos (surveys) junto a 72 e 234 respondentes, respectivamente. Em ambos os casos, a amostra foi não probabilística, selecionada por conveniência. Com isso, foi possível observar que ainda impera uma falta de hábito de planejamento prévio às compras por parte dos consumidores, o que contribui para um maior comportamento impulsivo no momento de decisão. Além disso, observou-se uma boa avaliação das ações de cross merchandising pelos consumidores, mesmo que eles entendam o objetivo e percebam sua influência.

Palavras-chave: Merchandising. Cross merchandising. Comportamento de compra. Consumidor.

\begin{abstract}
The objective of this work was to analyze the evaluation of the practice of cross merchandising in the opinion of consumers. Initially, a literature review was performed, focusing on the discussion about merchandising, its origin and evolution, its concept and its importance, entering into the practice of cross merchandising. Having literature as support, a methodological approach was adopted, with an exploratory approach, carried out by means of two quantitative surveys (surveys) with 72 and 234 respondents, respectively. In both cases, the sample was non-probabilistic, selected for convenience. This way, it was possible to observe that there is still a lack of planning habits prior to purchases on part of the consumers, which contributes to a more impulsive behavior at the moment of decision. In addition, a good evaluation of cross-merchandising actions by consumers was observed, even if they understood the objective and perceived its influence.
\end{abstract}

Keywords: Merchandising. Cross merchandising. Buying behavior. Consumer.

Recebido em 07/05/2020. Aprovado em 02/07/2020. Avaliado pelo sistema double blind peer review. Publicado conforme normas da ABNT. http://dx.doi.org/10.22279/navus.2020.v10.p01-13.1276 


\section{INTRODUÇÃO}

A ação de divulgar um produto de forma que atraia a atenção dos consumidores tem se aprimorado, sendo crescentemente buscada e valorizada pelas organizações. Isso se torna especialmente importante quando se pensa no ponto de venda (PDV) e no momento de compra. O ponto de venda é considerado o único lugar em que se consegue unir o consumidor, o dinheiro e o produto, ou seja, onde o estímulo é divulgado e já recebido, podendo influenciar imediatamente a decisão de compra.

Nesse sentido, de acordo com um relatório divulgado pelo Instituto Nielsen (2015), estima-se que, em média, $70 \%$ das decisões dos consumidores são tomadas no ponto de venda, nas quais se gastam aproximadamente 15 segundos. Ainda, o relatório aponta que praticamente $40 \%$ dos produtos dispostos no ponto de venda acabam nem sendo notados pelo consumidor. O fato de o consumidor já estar no local e com o produto a sua disposição transforma o momento propício para a compra, muitas vezes sem pensar se existe a necessidade de aquisição.

Ainda, em relação ao comportamento de compra, $61 \%$ dos participantes da pesquisa relataram ter planejado a compra previamente (NIELSEN, 2015). Além disso, quando indagados acerca da influência do ambiente de venda, $39 \%$ relataram que foram lembrados de determinados produtos no momento da compra, sendo que, destes, $22 \%$ disseram que precisavam do produto e $17 \%$ falaram que não precisavam. Esses dados demonstram, em primeiro lugar, que o comportamento de compra planejada ainda não é adotado em grande massa pelos consumidores. Em segundo lugar, observa-se a grande capacidade de influência do ponto de venda nas decisões dos consumidores no momento da compra.

Assim, evidencia-se a importância do ponto de vendas e a necessidade de gerenciar os esforços desenvolvidos nele. Independente da concepção que se tem acerca do ato de comprar, seja de algo rápido e automático, ou de algo agradável e divertido, o fato é que a inovação no ponto de venda se torna imprescindível. Os clientes precisam que o produto seja de fácil acesso, em pontos estratégicos, e onde eles já estejam acostumados a encontrar, com o máximo de informações expostas de maneira simples e clara.

Nesse sentido, o merchandising se apresenta como um dos pilares principais do ponto de venda, contribuindo para uma boa administração dos produtos, bem como, por consequência, proporcionando um aumento em suas vendas. Dessa forma, o merchandising nada mais é que toda ação e divulgação no ponto de venda, tudo aquilo que chama a atenção do consumidor no momento da compra, e o atrai, a fim de estimular a sua decisão.

Uma das principais técnicas de merchandising é o cross merchandising, que consiste na disposição estratégica de produtos de consumo conjunto de forma próxima. Essa ação tem como intuito lembrar o consumidor de produtos que ele poderia esquecer, como, por exemplo, colocando o queijo ralado próximo ou ao lado do molho de tomate. Assim, pode-se dizer que ela contribui para entregar maior facilidade e comodidade ao consumidor, especialmente em relação a produtos de menor valor, que são menos lembrados.

À luz do exposto, o trabalho teve como objetivo analisar a avaliação da prática de merchandinsig na opinião dos consumidores. Procedeu-se, inicialmente, a uma revisão da literatura, focando na discussão acerca do merchandising, sua origem e evolução, seu conceito e sua importância, discorrendo também sobre suas principais práticas, como o cross merchandising. Além disso, importantes distinções foram feitas entre o termo e outros dois tratados como similares, como o product placement e a promoção de vendas, a fim de dirimir eventuais confusões conceituais. Tendo a literatura como suporte, adotou-se metodologicamente, uma abordagem quantitativa, de cunho exploratório, realizada por meio de dois levantamentos quantitativos (surveys) junto a 72 e 234 respondentes, respectivamente, compondo, em ambos os casos, uma amostra não probabilística, selecionada por conveniência.

\section{MERCHANDISING}

O termo merchandising tem origem da palavra inglesa merchand, que, por sua vez, derivou do francês merchandiser, que significa negociante. Outra possibilidade é a origem da palavra inglesa merchandise, que 
significa mercadoria. Ou seja, em ambos os casos, a etimologia da palavra contribui para denotar a ênfase em negociar a mercadoria.

Apesar disso, na tradução para o português, foi-se denominado de "mercadização", ou seja, uma junção de mercado e ação, o que acabou fugindo do contexto original (BLESSA, 2005), por se aproximar mais do conceito de marketing, do que de merchadising de fato. Uma tradução mais adequada seria de "mercadorização", ou, ainda, "mercadoriando", dando a entender o significado de colocar a mercadoria em ação ou movimento.

Blessa (2005) defende que o merchadinsing sempre esteve presente no comércio, desde a Idade Média, ainda que não de maneira formal. Tal prática começou a ganhar atenção com o passar dos anos, conforme os comerciantes foram notando que as mercadorias que eram expostas de forma mais visível eram mais vendidas do que aquelas que não estavam nas vitrines (BLESSA, 2005). Segundo a autora, foi a partir de 1930 que o termo ganhou maior popularidade, sendo intensificado pelo movimento de autosserviço que acontecia nos Estados Unidos, quando iniciava a necessidade de se destacar o produto, para que o próprio consumidor o visse e o selecionasse, tendo em vista que não mais haveria o auxílio de balconistas ou funcionários para atendimento.

Dessa forma, o meio empresarial começou a perceber uma relação entre a exposição da mercadoria e a atração da atenção e do interesse do consumidor, bem como destas com a intenção de compra (CABRAL; GHISLENI, 2018). Isto é, passa-se a acreditar que quanto mais visível estiver uma mercadoria, maior a possibilidade de o consumidor prestar atenção e ser atraído por ela, o que também tende a aumentar a sua possibilidade de compra. Essa responsabilidade de disponibilizar o produto de forma a chamar a atenção do consumidor e eventualmente gerar o interesse nele é do merchandising.

Sendo assim, o merchandising pode ser concebido como o conjunto de técnicas e ações utilizadas no ponto de venda com o intuito de divulgação de um produto, proporcionando melhor visibilidade de bens, serviços e/ou marcas (BLESSA, 2005; LIMEIRA, 2006). Ao fazer isso, tem-se como objetivo influenciar e motivar as decisões de compra dos consumidores, justamente no momento do processo decisório (BLESSA, 2005; LIMEIRA, 2006). Ou seja, trata-se da utilização de diferentes maneiras para atrair o olhar e a atenção do consumidor, no intuito de, assim, promover e impulsionar a decisão de compra no momento propício a isso.

Nesse sentido, Limeira (2006) afirma que as ações realizadas no ponto de venda têm grande poder de influência no comportamento do consumidor, visto que, muitas vezes, a decisão do consumidor é tomada justamente no ponto de venda, a partir dos estímulos recebidos nele. Corroborando com isso, Tota e Colucci (2003) defende que a prática estratégica de exposições é fundamental para colocar o produto certo no lugar e na quantidade adequadas, contribuindo para que lhes sejam dados o impacto necessário para que seus atributos sejam perceptíveis.

Por esse motivo, alguns pontos são tidos como primordiais para a obtenção de êxito. Nos dias atuais, o tempo está cada vez mais curto, com o sentimento de que a vida está "correndo" e com cada vez mais coisas a se fazer. Como consequência, as decisões tomadas no ponto de venda acontecem de maneira bastante rápida, estimada em segundos, com a menor intenção de esforço por parte do consumidor. Além disso, em contraposição, há quem argumente que o ato de ir às compras, nesse contexto, acaba sendo visto como algo prazeroso, próximo a um entretenimento, no qual os consumidores vivem uma verdadeira experiência de diversão (PINHO, 2006).

Silva (1990, p. 17) completa definindo merchandising como "o planejamento e a operacionalização de atividades que se realizam em estabelecimentos comerciais, principalmente em lojas de varejo e de autosserviço", compondo o complexo composto mercadológico de bens de consumo. Ainda, declara que "o merchandising tem como objetivo expor esses bens ou apresentá-los de maneira adequada e destacada, a fim de que sejam criados impulsos de compra nos consumidores ou usuários, contribuindo para tornar mais rentáveis todas as operações nos canais de marketing".

Mais do que impulso de compra, pretende-se, com a prática do merchandising, encurtar o ciclo de adoção do produto por parte do consumidor, incentivando-o que passe rapidamente pelas fases de conscientização, interesse e avaliação, comprando-o para futura experimentação. Considerando a natural 
resistência a novidades por grande parte dos consumidores, as ações de merchandising podem contribuir para diminuir essa barreira, fomentando a primeira compra.

\subsection{Visual merchandising e cross merchandising}

O merchandising engloba a compreensão de todo o espaço disponível no ponto de venda, desde a fachada até o seu interior, identificando os locais de maior visualização e mesmo de maior movimentação das pessoas. Assim, cada gôndola, prateleira, chão, corredor, e inclusive os caixas, tudo deve ser considerado como potencial ponto de ação de merchandising, utilizando diferentes maneiras de exposição para aumentar a chance de os produtos serem notados.

Nesse contexto, viu-se a necessidade de aprimorar as técnicas do merchandising, que deve ser pensada de forma mais abrangente e complexa; com isso, vem se revelando o Visual Merchandising (FERREIRA; BRASIL AYRES; PAGNOSSIN, 2019). Segundo Las Casas (2012), o Visual Merchandising é tudo que envolve a organização e padronização do ambiente no ponto de venda, tendo como principal característica criar um clima no ambiente no qual o consumidor consiga se sentir atraído a adquirir o produto. Implica como a mobília, iluminação, som, aroma, tudo que remete ao cliente a lembrança do produto. Como por exemplo quando entramos em um supermercado e está tocando uma música mais alegre. Ou em alguma loja infantil, e é possível sentir um aroma de perfume ou talco para bebê. Tudo isso são atrativos para puxar a memória do cliente.

Dentre as principais ações de merchandising, especialmente Visual Merchandising, destaca-se o cross merchandising, quando é realizada uma ligação ou cruzamento entre um produto e outro similar, apresentando-os de forma próxima, mesmo que distantes da sua seção tradicional (BLESSA, 2005; CABRAL; GHISLENI, 2018). São exemplos de ações de cross merchandising quando estrategicamente o queijo ralado (em um clip strip) é posicionado ao lado do molho de tomate ou do macarrão, quando a seção de produtos associados a churrasco é disposta próximo ao açougue, ou mesmo quando são montadas ilhas de sucrilhos junto ao corredor de laticínios. A ideia é lembrar o consumidor da associação no consumo e, como consequência, da necessidade de comprar conjuntamente, ambos os produtos indicados.

Ressalta-se que essa ação é interessante por não incentivar a compra por impulso por si só, meramente, segundo a qual o consumidor acaba comprando o que não havia planejado, mas sim estimular a compra cruzada ou por associação. Ou seja, defende-se que esta ação serve para lembrar o consumidor de um item quando estiver comprando algum produto que geralmente é consumido com ele. Com isso, conseguese aumentar as vendas de diversos produtos que normalmente são esquecidos pelos clientes, ainda que sejam considerados como necessários. Pode-se argumentar que se trata sim de uma compra por impulso, mas racionalizada.

\subsection{Confusões conceituais}

Apesar da conceituação aqui exposta, cabe pontuar que existe uma confusão conceitual em relação ao merchandising, muitas vezes aplicado e/ou usado equivocadamente com outras áreas, filosofia ou aplicações do marketing. Esses equívocos permeiam não só o senso comum, mas também o meio empresarial e, mais agravante, inclusive o âmbito acadêmico.

O primeiro grande exemplo é o Product Placement. De acordo com Helena e Pinheiro (2012), o product placement consiste na ação de inserção de produtos e/ou marcas na mídia, seja em programas de televisão, filmes, séries, vídeos de canais on-line, entre outros. Nestes casos, os produtos aparecem como se fossem adornos, de consumo normal, ou seja, as empresas usam um ou mais personagens que aparecem consumindo de forma natural o produto. Ou seja, enquanto o merchandising se refere às ações no ponto de venda, o product placement consiste na inserção de produtos e marcas em mídias televisas ou digitais.

Um segundo exemplo consiste na promoção de vendas. A promoção de vendas consiste em uma ação de condição temporária, que tem como objetivo agilizar o processo decisório, incentivar a compra e impulsionar a quantidade comprada. Essas ações podem ser realizadas dentro ou fora do ponto de venda. No 
ponto de venda, por exemplo, podem ser utilizados promotores, com distribuição de degustações; nestes casos, o intuito da ação promocional é de atrair o consumidor, sendo posicionado em um local de maior fluxo, e que destaque a ser uma vantagem para o cliente. Já fora do ponto de venda, são exemplos as campanhas promocionais, a distribuição de brindes ou amostras grátis em revistas ou junto a outros produtos similares. Dessa forma, a promoção de venda pode envolver as próprias ações de merchandising, mas não se limita a ele.

\section{MÉTODO DA PESQUISA}

O trabalho adotou uma abordagem quantitativa, de cunho exploratório, realizada por meio de dois levantamentos quantitativos (surveys). Assim, foram coletados dados primários por meio da aplicação de questionários via plataforma online, junto a 72 e 234 respondentes, respectivamente. Em ambos os casos, a amostra foi não probabilística, selecionada por conveniência.

\subsection{Instrumento de pesquisa}

O questionário foi composto por três blocos principais. Antes de iniciar, havia um termo de consentimento, de participação livre e voluntária, com posterior publicação dos dados, o qual o respondente deveria assentir para dar continuidade.

Em primeiro lugar, analisou-se, de maneira geral, o comportamento de compra, especialmente em relação à compra por impulso. Dessa forma, foi disposta uma escala de diferencial semântico com cinco frases, todas elas nas quais o respondente deveria atribuir seu nível de concordância, de 0 a 10 . As quatro primeiras questões foram elaboradas para esse estudo, sendo uma delas de escala reversa, enquanto a quinta foi utilizada de Costa, Paula, Angelo e Fouto (2017) para mensurar a compra por impulso (também de escala reversa).

Quadro 1 - Comportamento de compra

1. Sempre faço lista de compras quando vou ao mercado.

2. Fazer lista de compras antecipadamente, me faz comprar apenas o que consta nela.

3. Nunca comprei algo que não fosse realmente necessário.

4. Geralmente compro produtos que não tinha intenções de adquirir antes de entrar na loja.

5. Sinto-me bastante influenciado a comprar mais do que deveria no momento de compra.

Fonte: elaboração própria (2020).

Em segundo lugar, foram apresentadas algumas ações de cross merchandising, sendo que, para cada um, os participantes deveriam avaliá-las, atribuindo seu nível de concordância a nove assertivas de uma escala de diferencial semântico, novamente em uma escala de 0 a 10. A escala foi dividida de forma equilibrada, com três assertivas positivas (1-3), três negativas (4-6) e três neutras (7-9).

Primeiramente, as ações de cross merchandising foram divididas em dois grupos: o primeiro com as ações de clip strip e o segundo com as ações de ilha, conforme Figura 1. Assim, foi solicitado aos primeiros respondentes que avaliassem as nove assertivas para cada bloco, a fim de verificar eventuais diferenças significativas entre eles. Dessa forma, 72 participantes assim o fizeram, respeitando-se o indicado de cinco respostas para cada variável (HAIR et al, 2009). Apesar disso, não foram encontradas diferenças significativas entre os blocos de ações, conforme será apresentado de forma mais detalhada no tópico seguinte. Por esse motivo, optou-se pela junção das ações, condensando os grupos a fim de se formar apenas um objeto de avaliação para os demais respondentes. 
Figura 1 - Ilustração das ações de cross merchandising
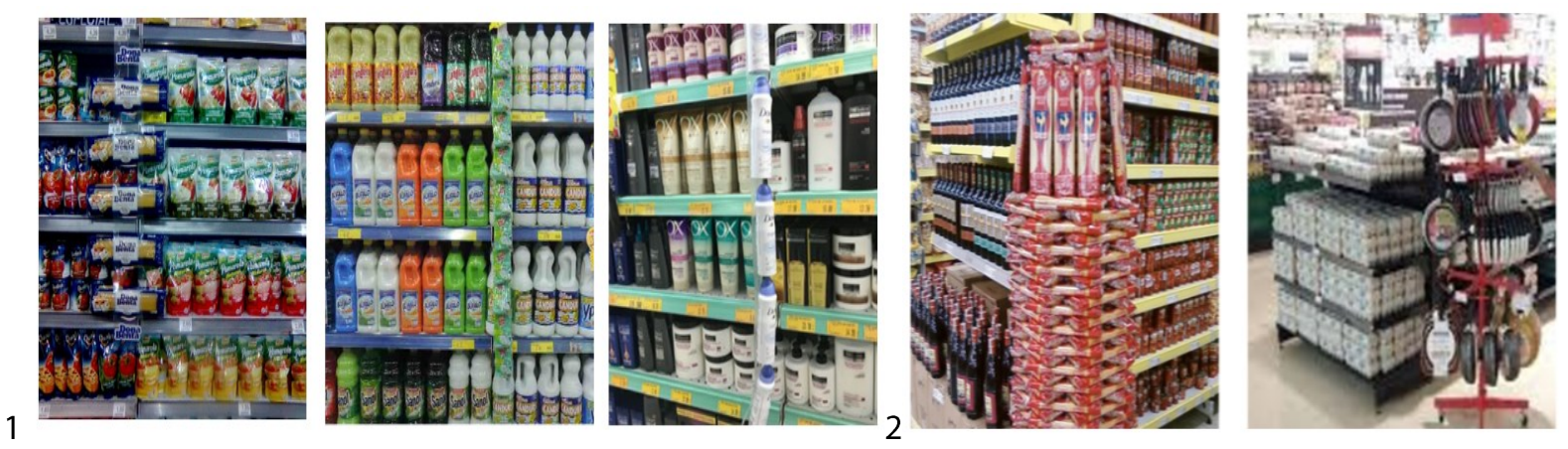

Fonte: elaboração própria (2020).

Quadro 2 - Avaliação Merchandising
1. Essas ações me lembram de produtos que geralmente esqueço.
2. Gosto disso porque me ajuda no momento de compra.
3. Essas ações são ótimas, facilitam as decisões do consumidor.
4. Esse tipo de ação me faz gastar muito mais.
5. Sinto-me obrigado a comprar quando vejo junto.
6. A intenção é forçar que eu compre algo que não preciso.
7. Não me vejo influenciado por essas ações.
8. Praticamente ninguém presta atenção nessas ações, então não faz diferença.
9. Nunca vi esse tipo de prática antes.

Fonte: elaboração própria (2020).

Por fim, havia o perfil do respondente, com a identificação do sexo, idade, escolaridade e renda familiar mensal. A última pergunta buscou investigar o conhecimento dos participantes acerca da prática de cross merchandising, indagando, de forma aberta, se eles sabiam mencionar o nome dado a essas ações.

O questionário passou por um pré-teste conceitual junto a um júri de especialistas, formado por três profissionais formados e atuantes na área mercadológica, tanto acadêmica quanto empresarialmente. Somente após isso, o questionário foi considerado apto para aplicação.

\subsection{Técnicas de análise de dados}

Foram utilizadas algumas técnicas de análise de dados. Em primeiro lugar, foi realizada a estatística descritiva básica. Em segundo lugar, possíveis diferenças entre os grupos de participantes foram verificadas, adotando-se o teste estatístico paramétrico t. No caso das escalas, foram rodadas Análises Fatoriais Exploratórias. De forma complementar, também o teste de correlação paramétrico de Pearson foi utilizado.

\section{APRESENTAÇÃO E ANÁLISE DOS DADOS}

A seguir, são apresentados e analisados os dados dos levantamentos.

\subsection{Primeiro levantamento quantitativo}

A amostra ( $n=72$ ) foi composta por uma maioria de respondentes do gênero feminino $(66,1 \%)$, com baixa renda (58,9\% até $R \$ 2.900$, seguido de $30,4 \%$ entre $R \$ 2.900$ e $R \$ 7.250$ ) e escolaridade de ensino superior ( $58,9 \%$ entre cursando e concluído, seguido de $30,4 \%$ de ensino médio completo). A idade média foi de 32 anos (variando entre 18 e 62). $O$ tempo médio de resposta foi de cinco minutos. 
Para a primeira escala, sobre o comportamento geral de compra, rodou-se uma análise fatorial exploratória, cujos resultados atendem aos pressupostos de consistência, tais como: tamanho mínimo da amostra de cinco participantes para cada variável; normalidade multivariada dos dados; testes de KaiserMeyer-Olkin (KMO) maior que 0,5; teste de Esfericidade de Bartlett significativo (menor que 0,5); Mensure of Sampling Adequancy (MSA) superior a 0,5; comunalidade superior a 0,5; e variância total explicada superior a 0,5 (HAIR; BLACK; BABIN; ANDERSON; TATHAM, 2006).

Nesse sentido, obteve-se KMO de 0,552 ( $p=0,000)$, com MSA de todas as variáveis e comunalidades acima do estabelecido. Dessa forma, todas as variáveis atingiram os requisitos, não havendo, assim, indicação estatística de nenhuma exclusão. Ressalta-se que o modelo obteve $63,5 \%$ da variância total explicada, com a composição de dois fatores, que tiveram semelhança de variância (31,1\% e 31,4\%, respectivamente). O primeiro fator, de perspectiva de comportamento planejado, juntou as três primeiras assertivas, de sempre fazer lista prévia, de que isso ajuda a manter as compras de forma planejada e de que nunca havia comprado algo além do necessário. O segundo fator, por outro lado, de perspectiva de comportamento por impulso, agrupou as duas assertivas restantes, de que geralmente compra além do planejado e de que se sente bastante influenciado a isso.

Quadro 3 - Composição dos Fatores do Comportamento de Compra e Médias

\begin{tabular}{|l|c|c|c|}
\hline & Planejado & Impulso & Média \\
\hline Sempre faço lista de compras quando vou ao mercado &, 737 & 4,4 \\
\hline $\begin{array}{l}\text { Fazer lista de compras antecipadamente me faz comprar apenas o que } \\
\text { consta nela }\end{array}$ &, 730 & 5,3 \\
\hline Nunca comprei algo que não fosse realmente necessário &, 724 & & 2,9 \\
\hline Geralmente compro produtos que não tinha intenções de adquirir &, 868 & 5,1 \\
\hline $\begin{array}{l}\text { Sinto-me bastante influenciado a comprar mais do que deveria no } \\
\text { momento de compra }\end{array}$ &, 886 & 5,1 \\
\hline
\end{tabular}

Fonte: Dados extraídos da Rodada de Análise Fatorial Exploratória (2020).

Analisando as assertivas da escala, todas elas tiveram respostas variando entre 0 e 10 . Em relação a sempre fazer lista de compras, a média foi de 4,4, com moda de 0 , indicando que há uma tendência dos respondentes não se programarem para as compras. Já acerca da segunda afirmação (fazer lista de compras antecipadamente faz comprar apenas o que consta nela), a média foi de 5,3, com moda de 5, o que mostra que o consumidor entende que fazer uma lista prévia auxilia que a tomada de decisão no ambiente de compra seja condizente com o planejado. Sobre nunca comprar além do necessário, a média caiu para 2,9, com moda de 0 , indicando um comportamento impulsivo de compra. Isso foi corroborado com a quarta assertiva, de que geralmente compram produtos que não tinham intenção prévia, cuja média foi de 5,1, com moda de 10 , reforçando a compra além do planejado. Por fim, referente a se sentir bastante influenciado a comprar mais no momento de compra, obteve-se uma média de 5,1, com moda de 0 , indicando uma certa indiferença dos participantes em relação à influência do ambiente de compra.

Concernente aos fatores criados, o fator de comportamento de compra planejada apresentou uma média de 4,2, enquanto o de comportamento de compra impulsiva ficou com média de 5,1. Isso significa que, por um lado, o hábito de se planejar previamente às compras ainda não parece ser adotado pelos consumidores. Além disso, por outro lado, o consumidor pareceu se mostrar indiferente em relação ao comportamento impulsivo de compra.

Também para a segunda escala, de avaliação específica da ação de cross merchandising, rodou-se uma análise fatorial, cujos resultados atendem aos pressupostos de consistência, tais como: tamanho mínimo da amostra de cinco participantes para cada variável; normalidade multivariada dos dados; testes de KaiserMeyer-Olkin (KMO) maior que 0,5; teste de Esfericidade de Bartlett significativo (menor que 0,5); Mensure of Sampling Adequancy (MSA) superior a 0,5; comunalidade superior a 0,5; e variância total explicada superior a 0,5 (HAIR; BLACK; BABIN; ANDERSON; TATHAM, 2006). Nesse sentido, obteve-se KMO de 0,632 ( $p=0,000)$, com MSA de todas as variáveis e comunalidades acima do estabelecido. Dessa forma, todas as variáveis atingiram 
os requisitos, não havendo, assim, indicação estatística de nenhuma exclusão. Ressalta-se que o modelo obteve $69 \%$ da variância total explicada, com a composição de três fatores, os dois primeiros mais expressivos e o terceiro um pouco menos (26,4\%, $25,7 \%$ e $16,9 \%$, respectivamente).

O primeiro fator foi de perspectiva de avaliação positiva, juntando as três primeiras assertivas, de que a ação os lembra de produtos que geralmente esquece, de que gosta porque os ajuda e de que são ótimas, porque facilitam as decisões. O segundo fator, por outro lado, foi de perspectiva negativa, agrupando três assertivas, de que os fazem gastar mais, que se sentem obrigados a comprar e de que a intenção é forçar de que compre o que não se precisa. E por fim, o terceiro fator teve perspectiva neutra, condensando as três assertivas restantes, de que não se veem influenciados, de que ninguém presta atenção e de que nem viu essa prática antes.

Quadro 4 - Composição dos Fatores de Avaliação do Cross Merchandising e Médias

\begin{tabular}{|c|c|c|c|c|c|}
\hline & Positivo & Negativo & Neutro & Tira & Ilha \\
\hline$\checkmark$ A ação me lembra de produtos que geralmente esqueço & 768 & & & 5,89 & 6,09 \\
\hline$\checkmark$ Gosto disso porque me ajuda no momento de compra & ,926 & & & 6,68 & 6,14 \\
\hline$\checkmark$ Essas ações são ótimas, facilitam as decisões do consumidor & 884 & & & 7,14 & 6,32 \\
\hline X Esse tipo de ação me faz gastar muito mais & & ,893 & & 4,00 & 3,75 \\
\hline X Sinto-me obrigado a comprar quando vejo junto & & 807 & & 2,22 & 2,24 \\
\hline X A intenção é forçar que eu compre algo que não preciso & & ,741 & & 5,05 & 4,43 \\
\hline - Não me vejo influenciado por essas ações & & & 645 & 5,05 & 5,27 \\
\hline $\begin{array}{l}\text { - Praticamente ninguém presta atenção nessas ações, então } \\
\text { não faz diferença }\end{array}$ & & & 619 & 3,56 & 3,29 \\
\hline - Nunca vi esse tipo de prática antes & & & 771 & 2,24 & 2,41 \\
\hline$\checkmark$ Fator Positivo & & & & 6,57 & 6,18 \\
\hline $\mathrm{X}$ Fator Negativo & & & & 3,76 & 3,47 \\
\hline - Fator Neutro & & & & 3,62 & 3,66 \\
\hline
\end{tabular}

Fonte: Dados extraídos da Rodada de Análise Fatorial Exploratória (2020).

O intuito, neste primeiro momento, foi verificar eventuais diferenças percebidas entre a prática de cross merchandising em formato de tiras (clip strip) e de ilha, investigado por meio de um teste te amostras pareadas. Apesar disso, diferença significativa só foi verificada em relação a uma assertiva de perspectiva positiva (terceira), de que essas ações são ótimas porque facilitam a decisão $(t=2,039, p=0,046)$. Nesse sentido, melhor avaliação foi atribuída ao primeiro formato, de tira $(M=7,14, D P=2,75)$, em comparação ao formato de ilha $(M=6,32, D P=2,91)$, ainda que ambos tenham sido positivamente pontuados.

Dessa forma, todas as assertivas tiveram variações de resposta entre 0 e 10. Em relação à perspectiva positiva, as três assertivas (de que a ação lembra, de que gosta e de que a ação é ótima porque facilita) tiveram boas avaliações por parte dos respondentes. A primeira teve média 5,9 para o formato de tira e 6,1 para a ilha, enquanto a segunda subiu para média 6,7 e 6,2 e a terceira para 7,2 e 6,3, respectivamente. Isso culminou na boa avaliação do fator positivo criado, no qual as médias foram 6,6 para o cross merchandising em tira e 6,2 para o formato de ilha. Isso demonstra que os respondentes parecem gostar das práticas de cross merchandising, entendendo que elas os auxiliam no momento de tomada de decisão no ponto de venda.

Por outro lado, para a perspectiva negativa, as três assertivas (de que a ação faz gastar mais, de que força a comprar algo que não precisa e de que se sente influenciado) obtiveram avaliações entre ruins e intermediárias. A primeira teve média 4,0 para o formato de tira e 3,8 para a ilha, enquanto a segunda caiu para média 2,2 para a tira e 2,2 para a ilha e a terceira subiu para médias 5,1 e 4,4, respectivamente. Como consequência, houve uma avaliação desfavorável do fator negativo criado, no qual as médias foram 3,8 para o cross merchandising em tira e 3,5 para o formato de ilha, o que reforça que os respondentes gostam dessas ações, não vistas como de estímulo, invasivas nem de coerção.

O resultado supracitado se repetiu para a perspectiva neutra, também com as três assertivas (de não se sentir influenciado, de que ninguém presta atenção e de nunca ter visto antes) com avaliações entre ruins 
e intermediárias. A primeira frase teve média maior, de 5,1 para o formato de tira e 5,3 para a ilha, enquanto a segunda caiu para média 3,6 para a tira e 3,3 para a ilha e a terceira ainda mais, para médias 2,2 e 2,4, respectivamente. Por fim, a avaliação do fator neutro criado também foi desfavorável, com médias 3,6 para ambos os formatos. Ou seja, mesmo que os consumidores aleguem ver as ações e as identificar, acabam não as associando à possibilidade de influência.

Também foram verificadas eventuais diferenças de acordo com o gênero do respondente, investigadas por meio do teste $\mathrm{t}$ para amostras independentes. $\mathrm{O}$ teste de Levene de homogeneidade das variâncias não foi assumido, não sendo significativo em nenhum dos casos. Nesse sentido, foram encontradas diferenças significativas em relação ao comportamento impulsivo de compra, tanto acerca de cada uma das assertivas (de que compra mais e de que se sente influenciado a comprar mais, $t=3,137, p=0,003$ e $t=2,725$, $p=0,01$, respectivamente) quanto sobre o fator criado $(t=3,234, p=0,003)$. Em todos os casos, melhor avaliação foi realizada pelos respondentes do gênero feminino $(M=5,95, D P=3,45, M=6,03, D P=3,49$ e $M=5,99, D P=2,92$, respectivamente), em comparação ao gênero masculino $(M=3,26, D P=2,78, M=3,37, D P=3,43$ e $M=3,32$, $\mathrm{DP}=2,92$, respectivamente), ou seja, as mulheres relataram e parecem ter mais comportamento de compra impulsivo do que os homens.

Outra diferença significativa encontrada se referiu a uma assertiva de perspectiva positiva (de que a ação lembra) $(t=2,32, p=0,027)$, novamente com melhor avaliação por parte das respondentes mulheres $(M=6,62, D P=2,98)$, em comparação aos homens $(M=4,53, D P=3,31)$. Assim, as mulheres parecem ver de forma mais positiva as ações de cross merchandising, especialmente às de tiras, que as auxiliam a lembrar de eventuais produtos que acabariam esquecendo. Não foram encontradas diferenças significativas em relação à escolaridade nem à renda da amostra.

Por fim, quando questionados sobre a denominação das ações investigadas, menos da metade dos participantes $(41,7 \%)$ tentou responder. Destes, apenas $12,5 \%$ dos respondentes de fato acertaram, com a resposta merchandising. Houve confusão em relação aos termos marketing e pesquisa (ambos com $8,3 \%$ ), além de propaganda (5,6\%) e compra cruzada (2,8\%).

Sintetizando os resultados encontrados, em primeiro lugar, observou-se que os consumidores não adotam o hábito de se planejar previamente às compras, o que pode contribui para uma certa indiferença relatada acerca do comportamento impulsivo de compra. Apesar disso, as mulheres responderam por menor indiferença, indicando maior relato e prática de um comportamento impulsivo no momento da compra. Em segundo lugar, sobre as ações de cross merchandising, a avaliação foi bastante positiva, sugerindo que os consumidores as valorizaram porque os ajudam no momento da compra, lembrando de produtos que eventualmente poderiam esquecer. Também opinaram que tais ações são vistas e percebidas pelos consumidores no ambiente de compra, o que contribui para a sua capacidade de influência. Não obstante, ainda que eles não se sintam obrigados a comprar os produtos que são expostos juntos, os consumidores entendem o objetivo da prática, de influenciar a compra cruzada. Ainda, ambos os formatos de cross merchandising apresentaram avaliações similares, exibindo semelhança de percepção em relação a elas por parte dos consumidores. Também foi identificado que o público mais atraído por essas ações são as mulheres, que as avaliam mais positivamente, relatando que as ações auxiliam no momento da compra, enquanto para os homens, parece haver certa indiferença em relação a essa prática e sua influência.

\subsection{Segundo levantamento quantitativo}

A amostra $(n=234)$ foi composta por uma maioria de respondentes do gênero feminino $(56,8 \%)$, com baixa renda ( $58,7 \%$ até $R \$ 2.900$, seguido de $29,1 \%$ entre $R \$ 2.900$ e $R \$ 7.250$ ) e escolaridade de ensino superior (58,7\% entre cursando e concluído, seguido de $25,2 \%$ de ensino médio completo). A idade média foi de 33 anos (variando entre 15 e 80). O tempo médio de resposta foi de quatro minutos.

Repetiu-se a análise fatorial exploratória para a escala de comportamento de compra, obtendo-se resultado similar, com KMO de 0,577 ( $p=0,000)$ e 62,5\% da variância total explicada, a composição dos dois fatores anteriores, novamente com semelhança de variância (32,6\% e 29,9\%, respectivamente): um de 
perspectiva de comportamento planejado e outro de comportamento por impulso. Analisando as assertivas da escala, todas elas tiveram respostas variando entre 0 e 10.

Em relação à perspectiva de comportamento planejado de compra, as duas primeiras assertivas (fazer lista antecipadamente e fazer lista auxilia a tomada de decisão) tiveram médias favoráveis (5,2 e 5,8, respectivamente, além de modas de 0 e 10), reforçando o entendimento do consumidor acerca da importância de se planejar previamente, e de como isso auxilia que a tomada de decisão cumpra o que foi estipulado. Desta vez, os consumidores pareceram praticar mais o hábito de planejamento prévio. Sobre nunca comprar além do necessário, a média ficou em 3,4, com moda de 0 , novamente sugerindo um comportamento impulsivo de compra, que também foi reforçado pela assertiva de que compram produtos que não tinham intenção prévia, cuja média foi de 5,1, com moda de 10. Por fim, sobre se sentir bastante influenciado a comprar mais no momento de compra, a média foi de 5,7, com moda de 10, o que indica a capacidade de influência do ambiente de compra na visão dos próprios consumidores.

Nesse sentido, de forma semelhante ao levantamento anterior, o fator de comportamento de compra planejada apresentou uma média de 4,8, enquanto o de comportamento de compra impulsiva ficou com média de 5,4. Isso reforça, por um lado, a falta de hábito dos consumidores de se planejarem previamente às compras, o que pode contribuir, por outro lado, para a ocorrência do comportamento de compra impulsiva.

Outra análise fatorial exploratória foi rodada também para a escala de avaliação específica da ação de cross merchandising também com resultados semelhantes, tais como KMO de $0,682(p=0,000)$ e $62,3 \%$ da variância total explicada. Novamente, foram compostos os mesmos três fatores, o de perspectiva positiva mais expressivo, e os dois demais, de perspectivas negativa e neutra menos ( $27,7 \%, 17,4$ e $17,2 \%$, respectivamente). Dessa forma, todas as assertivas tiveram variações de resposta entre 0 e 10.

Em relação à perspectiva positiva, as três assertivas (de que a ação lembra, de que gosta e de que a ação é ótima porque facilita) tiveram boas avaliações por parte dos respondentes, com médias 5,3, 5,6 e 5,7, respectivamente. Isso ajudou na boa avaliação do fator positivo criado, cuja média foi de 5,5, novamente reforçando que os consumidores parecem gostar das práticas de cross merchandising. Por outro lado, referente à perspectiva negativa, as três assertivas (ação faz, obriga e força a gastar mais) tiveram avaliações divergentes. Assim, as duas primeiras tiveram avaliações ruins, com média de 4,4 e 2,3, respectivamente, sugerindo que os consumidores não acham que tais ações os estimulam a comprar mais, ou que se sentem obrigados a isso. Entretanto, a terceira frase teve avaliação favorável, com média de 6,0, indicando que, contraditoriamente, o consumidor acha que essas ações os forçam a comprar os produtos que são colocados juntos. Apesar disso, o fator negativo criado obteve média de 4,2, demonstrando que as ações, ainda assim, são vistas com bons olhos pelos respondentes. Sobre a perspectiva neutra, as três assertivas (ação não influencia, faz diferença e nunca viu antes) tiveram avaliações ruins dos respondentes, com médias 4,8, 3,1 e 2,2 , respectivamente. Por serem de ordem reversa, tais avaliações denotam, mais uma vez, que os consumidores percebem a capacidade de influência das referidas ações, corroborado pelo fator neutro criado, que obteve média de 3,4 .

Quadro 5 - Média das Assertivas e Fatores da Avaliação do Cross Merchandising

\begin{tabular}{|c|c|}
\hline$\checkmark \quad$ A ação me lembra de produtos que geralmente esqueço & 5,3 \\
\hline$\checkmark \quad$ Gosto disso porque me ajuda no momento de compra & 5,6 \\
\hline$\checkmark \quad$ Essas ações são ótimas, facilitam as decisões do consumidor & 5,7 \\
\hline X Esse tipo de ação me faz gastar muito mais & 4,4 \\
\hline X Sinto-me obrigado a comprar quando vejo junto & 2,3 \\
\hline X A intenção é forçar que eu compre algo que não preciso & 6,0 \\
\hline - Não me vejo influenciado por essas ações & 4,8 \\
\hline - Praticamente ninguém presta atenção nessas ações, então não faz diferença & 3,1 \\
\hline - Nunca vi esse tipo de prática antes & 2,2 \\
\hline$\checkmark \quad$ Fator Positivo & 5,5 \\
\hline $\mathrm{X}$ Fator Negativo & 4,2 \\
\hline - $\quad$ Fator Neutro & 3,4 \\
\hline
\end{tabular}

Fonte: elaboração própria (2020). 
Novamente, foram verificadas eventuais diferenças de acordo com o gênero do respondente, investigadas por meio do teste $\mathrm{t}$ para amostras independentes. $\mathrm{O}$ teste de Levene de homogeneidade das variâncias não foi assumido, não sendo significativo em nenhum dos casos. Foram encontradas as mesmas diferenças significativas do levantamento anterior, em relação ao comportamento impulsivo de compra, tanto acerca de suas assertivas (de que compra mais e de que se sente influenciado a comprar mais, $t=3,609, p=0,000$ e $t=2,801, p=0,006$, respectivamente) quanto sobre o fator criado $(t=3,631, p=0,000)$. Assim, repete-se a melhor avaliação por parte das respondentes mulheres $(M=5,80, D P=3,23, M=6,24, D P=3,05$ e $M=6,02, D P=2,83$, respectivamente), em comparação aos homens $(M=4,09, D P=3,44, M=4,97, D P=3,35$ e $M=4,53, D P=2,97$, respectivamente), reforçando um relato maior de hábito impulsivo de compra por elas.

Outra diferença significativa encontrada, está nova, referiu-se a duas assertivas de perspectiva negativa (de que a ação faz gastar muito e de que a intenção é forçar a comprar) ( $t=2,131, p=0,034$ e $t=-2,273$, $p=0,024$, respectivamente). Curiosamente, os resultados foram divergentes, com a primeira assertiva com melhor avaliação por parte das respondentes mulheres $(M=4,84, D P=3,34)$, em comparação aos homens $(M=3,82, D P=3,43)$, e a segunda ao contrário, com melhor avaliação dos homens $(M=6,62, D P=3,37)$, em comparação às mulheres $(M=5,51, D P=3,56)$. Assim, diferente do primeiro levantamento, as mulheres parecem sentir que as ações de cross merchandising influenciam no aumento da compra e do valor gasto mais do que os homens. Por outro lado, eles percebem essas ações como tentativas de influenciá-los a comprar coisas que eles não precisam, mais do que elas. Não foram encontradas diferenças significativas em relação à escolaridade, nem à renda da amostra.

Por fim, quando questionados sobre a denominação das ações investigadas, novamente menos da metade dos participantes (46,3\%) tentou responder, mas, destes, apenas $7,4 \%$ de fato acertaram a resposta merchandising, além de $4,1 \%$ que ficaram próximos do sentido da resposta, mas sem a correta denominação (exposição de produtos, utilização de gôndolas e prateleiras, entre outros). A maior parte das tentativas denominou de marketing (18,2\%).

Em síntese, primeiro, identificou-se que, novamente, a falta de hábito de planejamento prévio por parte dos consumidores, resultando em um maior comportamento impulsivo no momento de compra, quando comparado ao levantamento anterior. Também se repete a maior incidência de comportamento impulsivo por parte das respondentes mulheres. Em segundo lugar, sobre as ações de cross merchandising, a avaliação foi positiva, ainda que menos que no levantamento anterior. Isso corrobora a valorização da prática, vistas como de ajuda ao consumidor, que são visualizadas e percebidas de forma positiva por eles. Contudo, de modo diferente, além de entender o objetivo da prática, os consumidores também mostraram perceber a sua influência, sentindo que isso os faz comprar produtos que não precisariam. Em relação às diferenças de gênero, os homens percebem mais a tentativa de influência por parte desta prática, enquanto as mulheres parecem sentir mais de fato a influência no aumento da compra.

\subsection{Correlações}

Os fatores do comportamento de compra se mostraram significativamente correlacionados com os fatores de avaliação do cross merchandising, tanto no primeiro quanto no segundo levantamento. No primeiro, os fatores de avaliação dos formatos tira e ilha tiveram correlações positivas e fortes entre si, os positivos $(P=0,690, p=0,000)$, os negativos $(P=0,743, p=0,000)$ e os neutros $(P=0,579, p=0,000)$, o que explica a falta de diferença encontrada na avaliação dos dois formatos, reforçando a similaridade entre eles na visão do consumidor.

Ainda, o fator de comportamento de compra planejada exibiu correlação positiva com os fatores positivo e neutro de avaliação do cross merchandising de fita $(P=0,292, p=0,021$ e $P=0,343, p=0,006$, respectivamente), ou seja, quanto mais os consumidores relatam o hábito de se planejar previamente às compras, mais parecem avaliar positivamente as ações de cross merchandising. Já o comportamento de compra impulsiva apresentou correlação positiva com os fatores positivos e negativos de ambos os formatos (tira com $\mathrm{P}=0,256, \mathrm{p}=0,045$ e $\mathrm{P}=0,298, \mathrm{p}=0,022$, e ilha com $\mathrm{P}=0,474, \mathrm{p}=0,000$ e $\mathrm{P}=0,506, \mathrm{p}=0,000$, 
respectivamente). Isso indica que, por mais contraditório que pareça, quanto mais um consumidor se relatar impulsivo, também melhor e pior ele avalia as ações, possivelmente por gostar delas e valorizá-las, mas, ao mesmo tempo, perceber a influência que isso tem no seu comportamento de compra.

No segundo, o fator de comportamento de compra planejada exibiu correlação negativa com o comportamento de compra impulsiva $(P=-0,242, p=0,000)$, assim como positiva com os fatores de avaliação negativa e neutra do cross merchandising $(P=0,166, p=0,013$ e $P=0,264, p=0,000$, respectivamente). Ou seja, diferente do primeiro levantamento, quanto mais o consumidor declara que tem hábito de se planejar previamente às compras, pior tende a ser sua avaliação das ações. Por outro lado, o comportamento de compra impulsiva apresentou correlação positiva com os fatores positivo e negativo de avaliação do cross merchandising $(P=0,305, p=0,000$ e $P=0,240, p=0,000$, respectivamente), reforçando o resultado encontrado no primeiro levantamento.

\section{CONSIDERAÇÕES FINAIS}

O trabalho teve como objetivo analisar a avaliação da prática de cross merchandinsig na opinião dos consumidores. Assim, foi possível observar, em primeiro lugar, que ainda impera uma falta de hábito de planejamento prévio às compras, o que contribui para um maior comportamento impulsivo no momento de decisão, especialmente entre as mulheres. Em segundo lugar, as ações de cross merchandising foram bem avaliadas, vistas como de ajuda no momento de compra, mesmo que eles entendam o objetivo e percebam sua influência, no sentido de que elas os fazem comprar produtos que a princípio não precisariam.

Como já constatado academicamente e, neste estudo, apontado pelos próprios respondentes, o consumidor se mostra bastante influenciável no momento da compra, não se planejando previamente, sendo propícia a probabilidade de se comprar mais do que o previsto. Os próprios consumidores reconhecem esse cenário, o que não pareceu ser suficiente para a mudança de hábito em relação ao comportamento de compra.

Como consequência, conforme defendido pela literatura, o merchandising e, mais especificamente, o cross merchandising, de fato tem importância no ponto de venda, podendo ser considerado como uma ação indispensável para a gestão do ambiente de loja. Essas ações, se bem planejadas e desenvolvidas, inclusive podem ser bem vistas pelos consumidores, mesmo cientes do estímulo a comprar e gastar mais.

Nesse sentido, o estudo contribui para agregar resultados empíricos à literatura de merchandising e cross merchandising, estendendo a compreensão acerca dessas práticas segundo a opinião do público mais importante, que são os consumidores. Também a questão do comportamento de compra foi enfatizada, o que permite uma visão mais sistêmica em relação a esse processo, discutindo-se variáveis pertinentes de forma conjunta.

Apesar disso, diante das limitações deste estudo, especialmente as provenientes da delimitação metodológica, as sugestões de pesquisas futuras são das mais variadas. Primeiro, a hipótese de possíveis diferenças de reações em relação às distintas formas de exposição de cross merchandising merece ser investigada mais a fundo. Outra possibilidade é a realização de um estudo diretamente no ponto de venda, abordando consumidores no momento da compra. Isso permitiria até mesmo verificar de fato o comportamento real de compra, indagando e verificando se houve um planejamento prévio e contrastando isso à aquisição de produtos não previstos, bem como ponderando frente às reações e às ações de cross merchandising na prática.

\section{REFERÊNCIAS}

BLESSA, R. Merchandising no ponto-de-venda. São Paulo: Atlas, 2005.

CABRAL, L. S.; GHISLENI, T. S. As ações de merchandising e as transformações no ponto de venda do varejo supermercadista. Temática, v. 14, n. 4, abr. 2018.

CELIA, E. R. Atingindo o consumidor de entretenimento on demand: product placement em House of Cards. LOGOS: Comunicação e Universidade, v. 24, n. 3, 2017. 
COSTA, MARCONI F.; PAULA, THAISA S.; ANGELO CLAUDIO F.; FOUTU, NUNO MANUEL M. D. Personalidade da marca, significado do produto e impulsividade na compra por impulso: um estudo em ambiente de shopping center. Recadm, IBEPES - Curitiba/PR, v.16, n. 2, 2017.

FERREIRA, A.; BRASIL AYRES, M.; PAGNOSSIN, L. Ambiente do visual merchandising em lojas de varejo de Santa Maria - RS. Revista sobre Excelência em Gestão e Qualidade, v. 1, n. 1, p. 25-34, out. 2019.

HAIR Jr., J.F.; BLACK, W.C.; BABIN, B.J.; ANDERSON, R.E.; TATHAM, R.L. Análise multivariada de dados. Porto Alegre: Bookman, 2009.

HELENA, R. S.; PINHEIRO, A. J. A. Muito além do merchan!. São Paulo: Elversier, 2012.

LAS CASAS, A. L. Administração de marketing: conceitos, planejamento e aplicações à realidade brasileira. São Paulo: Atlas, 2012.

LIMEIRA, T. M. V. Gestão de Marketing. São Paulo: Saraiva, 2006

NILSEN. Execução consciente: o gatilho certo para atrair os shoppers. Nilsen Imprensa. Disponível em: < https://www.nielsen.com/br/pt/press-releases/2017/execucao-consciente-o-gatilho-certo-para-atrair-osshoppers/. Acesso em: 10 maio 2019.

PINHO, J. B. Comunicação em Marketing. Campinas: Papirus, 2006.

SILVA, J. C. Merchandising no varejo de bens de consumo. São Paulo: Atlas, 1990.

TOTA, J.; COLUCCI, N. Gestão de Marketing no Varejo: A força do merchandising para o varejo moderno. São Paulo: 2003. 